\title{
Aspectos físico-ambientais da microbacia hidrográfica do riacho chafariz
}

\author{
Geoenvironmental analysis of watershed Fountain Creek \\ NASCIMENTO ${ }^{1}$, J. J. S.; GOÉS ${ }^{2}$, V. C.; SANTOS ${ }^{2}$, E. B. SILVEIRA ${ }^{3}$, T. A. \\ jeronimodesouza.sl@hotmail.com;
}

\begin{abstract}
Resumo
A bacia hidrográfica como uma unidade geográfica que compõe um sistema natural pode ser utilizada no planejamento na maior parte do mundo. A qual é de fácil reconhecimento e possível de ser caracterizada. O trabalho tem como objetivo caracterizar os aspectos físicos da microbacia hidrográfica do Riacho Chafariz. Para tanto, a metodologia consiste na aquisição de dados; tratamento destes dados, com emprego de métodos de determinados autores e de técnicas de geoprocessamento. E por fim, a da análise dos resultados, que possibilitaram compreender a microbacia hidrográfica. Segundo os resultados a microbacia possui uma área de drenagem de $215,58 \mathrm{Km}^{2}$, perímetro igual a 78,67 Km, coeficiente de compacidade $(\mathrm{K} c)=1,52$, fator de forma $(\mathrm{K} f)=0,216$, índice de circularidade $(\mathrm{I} c)=0.437$, índice de comprimento e área da bacia (Ico) $=1,70$, ordem fluvial da microbacia de $5^{\circ}$ ordem, densidade de drenagem (Dd) $=0.14 \mathrm{Km} / \mathrm{Km}^{2}$, extensão média do escoamento superficial $(l)=1,70 \mathrm{Km}$. Possui três classes de solo: Luvissolos, Latossolos e Neossolos. A altitude varia de $296 \mathrm{~m}$ a $872 \mathrm{~m}$. Conclui-se, que neste trabalho com a metodologia utilizada foi possível gerar informações que podem ser aplicadas em estudos ambientais na mesma ou em outras áreas com características semelhantes.
\end{abstract}

Palavras-chave: Riacho Chafariz, caracterização física, geoprocessamento.

\begin{abstract}
The watershed as a geographical unit that makes up a natural system can be used in planning in most parts of world. Which it is easily recognized and also can be characterized. The study had how objective to characterize the physical aspects of the Chafariz Stream micro watershed. Therefore, the methodology consists in the acquisition and processing of geographical and climatic data, with the use of geoprocessing techniques. The results made it possible to understand the dynamics of the watershed, which has a drainage area $=215,58 \mathrm{~km}^{2}$, perimeter $=78,67 \mathrm{~km}$, compacity coefficient $(\mathrm{Kc})=1,52$, form factor $(\mathrm{Kf})=0,216$, circularity index $(\mathrm{Ic})=0,437$, length index and area of the basin (Ico) $=1,70$, microbasin fluvial order of $5^{\text {th }}$, drainage density $(\mathrm{Dd})=$ $0,14 \mathrm{~km}^{2}$, average length of the flow surface $(1)=1,70$ $\mathrm{Km}$. It has three soil classes: Luvisols, Latosols and Neossolos, and average altitude varies from $296 \mathrm{~m}$ to $872 \mathrm{~m}$. Finally, concluded that this work was important because the used techniques and methodologies of Geoprocessing enabled to physically characterize of the micro basin of Chafariz Stream, and can be used for similar watersheds studies.
\end{abstract}

Keywords: Stream chafariz, physical characterization, geoprocessing.

\section{INTRODUÇÃO}

Devido sua importância, para gestão territorial e por ser um espaço geográfico em que acontecem diferentes interações naturais e antrópicas, as bacias hidrográficas tem sido locus para o desenvolvimento de diversos estudos. Entre os quais, se destacam os que abordam a bacia hidrográfica do ponto vista ambiental. Entretanto, ao comparar estes estudos nos diferentes biomas, as bacias hidrográficas do bioma Caatinga ainda são relativamente pouco estudadas.

Segundo Tucci (1997), uma bacia hidrográfica consiste na área limitada por divisores topográficos e composta de uma rede de drenagem formada pelos cursos de água - rio principal e 
seus afluentes, onde a captação natural da precipitação pluviométrica escoa de forma superficial convergindo para um único ponto de saída, o exutório.

Hidrologicamente, água que chega aos rios de uma bacia hidrográfica dependerá das suas características físicas, do regime de precipitação, das perdas por evapotranspiração e da infiltração. Logo, tais características são definidas pela geologia, a partir das diferentes litologias, pela geomorfologia através dos tipos de relevo, formas e orientações e pelos tipos de solos por meio das suas condições físicas, químicas e biológicas. Como também, da cobertura vegetal e do uso e ocupação do solo, portanto, todas estas características são importantes para a compreensão da dinâmica de uma bacia hidrográfica.

Conforme Rodrigues (2005), devido às peculiaridades naturais, a bacia hidrográfica é utilizada como referência espacial nos estudos físico-territoriais, contribuindo para o planejamento territorial e ambiental. As bacias hidrográficas são consideradas cenários de prováveis e diferentes tipos de degradação, assim, se faz necessário o seu monitoramento com o objetivo de compreender os processos atuantes diante dos usos de seus recursos naturais, na busca de minimizar os efeitos e impactos ambientais causados ao ambiente natural (ROCHA, 1991).

Villela e Mattos (1975) afirmam que as características físicas de uma bacia hidrográfica consistem em elementos relevantes no comportamento hidrológico. Tendo em vista a relação existente entre o regime hidrológico e estes elementos. Logo, os quais, quando correlacionados com dados hidrológicos conhecidos, possibilita inferir indiretamente valores para locais onde faltam informações. Segundo Novaes et al. (2004) o cálculo morfométrico de uma bacia hidrográfica se faz necessário para seu entendimento. Pois as feições geomorfológicas são relevantes para os trabalhos desenvolvidos que adotam a bacia como referência espacial. Sendo assim, os índices morfométricos são essenciais em estudos hidrológicos, auxiliando na definição de ações para possíveis intervenções nas bacias hidrográficas.

A compreensão destas feições em uma bacia hidrográfica a partir da aplicação dos índices morfométricos, permite obter informações importantes no que diz respeito à relação solo-superfície. Tendo em vista que as características geométricas estão intrínsecas ao comportamento da bacia hidrográfica, relacionando-se com o armazenamento de água e com o escoamento ocorrido na bacia (VILLELA e MATOS, 1975).

As técnicas de geoprocessamento tem apresentado significativa relevância, ao serem utilizadas no planejamento territorial urbano e rural. Logo, a realização de uma caracterização física, nas bacias hidrográficas pode ser feita com o suporte destas técnicas. As quais são importantes ferramentas para auxiliar nas tomadas de decisões na busca da resolução de problemas. O crescente uso destas técnicas atribui-se a popularização e disponibilidade gratuita dos dados 
geográficos e cartográficos, a oferta de dados primários com significativa qualidade e à diminuição nos custos econômicos e no tempo que são aplicadas em estudos ambientais.

Rosa (2005) define o Geoprocessamento como o conjunto de tecnologias utilizadas para coletar, processar, analisar e disponibilizar informações georreferenciadas. Câmara et al. (1999) afirmam que este termo consiste em uma área do conhecimento que utiliza métodos matemáticos e computacionais para o tratamento de informações geográfica. De maneira geral, compreende-se que o Geoprocessamento diz respeito a um conjunto de técnicas aplicadas na coleta, no tratamento e na manipulação de dados georreferenciados, onde a partir dos quais são geradas informações espaciais voltadas para um objetivo específico.

Entre as técnicas de geoprocessamento utilizadas nos estudos ambientais em bacias hidrográficas, destacam-se as oriundas do Sensoriamento Remoto, o qual no âmbito conceitual do Geoprocessamento consiste na obtenção de informações sem quem haja um contato direto com o objeto que se pretende estudar. Como também, os Sistemas de Informações Geográficas - SIG que auxiliam no tratamento dos dados, disponibilizando posteriormente as informações geradas.

Portanto, entende-se que estudos sobre aspectos ambientais precisam ser desenvolvidos, para que seja possível ter conhecimento da situação das bacias hidrográficas. Este trabalho tem como objetivo realizar a caracterização físico-ambiental da microbacia hidrográfica do Riacho Chafariz, utilizando técnicas de Geoprocessamento.

\section{METODOLOGIA}

\section{Localização da área de estudo}

A área objeto de estudo deste trabalho corresponde a microbacia hidrográfica do Riacho Chafariz, localizada entre as coordenadas do Sistema Universal Transversal de Mercator - UTM 9.245.000 mE e $730.000 \mathrm{mN}$ e $9.210 .000 \mathrm{mE}$ e $748.000 \mathrm{mN}$. A referida microbacia compreende partes dos municípios de Junco do Seridó, Salgadinho, Santa Luzia e São José do Sabugi, inseridos na Mesorregião Geográfica da Borborema, Estado da Paraíba. Possui uma área de drenagem correspondente a 215,58 $\mathrm{Km}^{2}$, é formada pelo Riacho Chafariz e seus afluentes (Figura 1). 

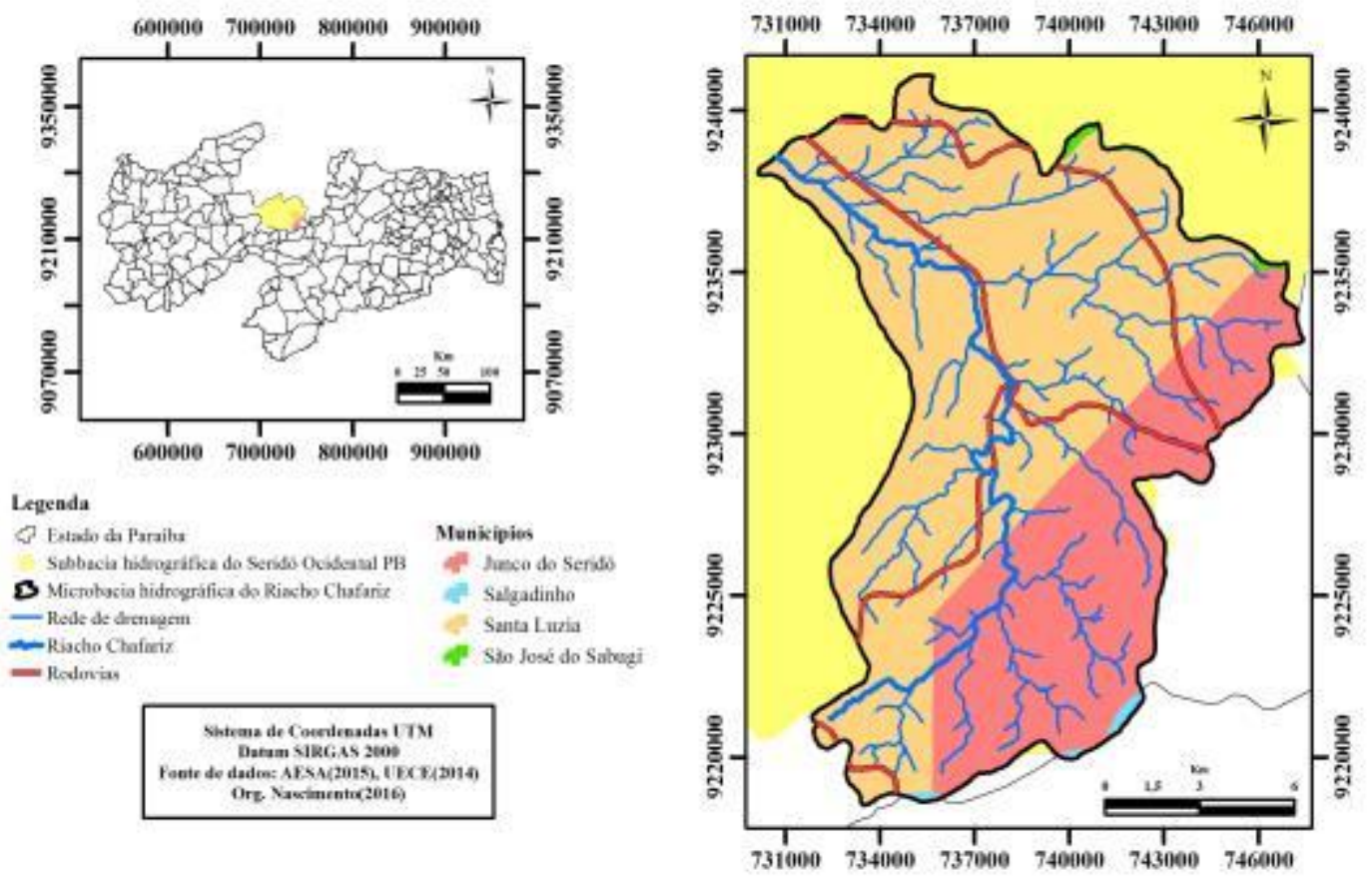

Figura 1 - Mapa de localização geográfica da microbacia hidrográfica do Riacho Chafariz. Fonte: AESA (2011) /UECE (2014). Elaborado por Nascimento et al. (2016).

\section{Obtenção dos dados}

Foram obtidos junto ao projeto Topodata do Instituto Nacional de Pesquisas Espaciais INPE, dados das cartas SB-24-Z-B e SB-24-Z-D, no formato GEOTIFF (16 bits), resolução espacial de 30m, Sistema de Coordenadas Geográficas e Datum WGS-84. Os quais são derivados dos dados do Shuttle Radar Topography Mission - SRTM no ano de 2000. Nas demais produções cartográficas, foram utilizados dados vetoriais da Agência Executiva de Gestão das Águas do Estado da Paraíba - AESA/PB e Universidade Estadual do Ceará - UECE, tais como: limites da região Nordeste, Estado da Paraíba, municípios, bacias hidrográficas, solos e toponímia de rios, nos formatos shapefile, Sistema de Coordenadas Geográficas e Datum SIRGAS 2000.

\section{Processamento dos dados}

Nesta etapa do trabalho foi utilizado o software de SIG ArcGIS 10.1, a partir da licença concedida pelo IFPB - Campus Picuí. Para tanto, criou-se um banco de dados geográficos para armazenar os dados e informações, com o objetivo de gerar diferentes produtos cartográficos. Adotou-se o sistema de projeção cartográfica UTM e o Datum SIRGAS 2000 para a zona 24 Sul. Desta forma, a partir da extração do Modelo Digital de Elevação - MDE da imagem SRTM através das ferramentas do ArcGIS 10.1, foi realizada para a microbacia hidrográfica do Riacho Chafariz a direção de fluxo, o fluxo acumulado, a delimitação, a extração da rede drenagem e a hierarquia fluvial conforme o método de Strahler (1957). 
Ainda foram considerados outros aspectos físico-ambientais da microbacia, tais como: hipsometria, declividade e tipos de solo. Para o mapa de classes de altitudes, foram usadas as informações extraídas do MDE. As classes de declividade da microbacia foram geradas e classificadas em seis intervalos distintos sugeridos pela EMBRAPA (1979). E o mapa de tipo de solo feito a partir da classificação feita pelo Sistema Brasileiro de Classificação de Solo - SBCS (EMBRAPA, 2013). Acerca dos cálculos morfométricos da microbacia do Riacho Chafariz, foram calculados os parâmetros físicos: área de drenagem (A), perímetro da microbacia (P). Como também os índices morfométricos descritos a seguir:

- Coeficiente de compacidade:

$$
K_{c}=0,28 \frac{P}{\sqrt{A}}
$$

- Fator de forma

$$
K_{f}=\frac{A}{L^{2}}
$$

- Índice de Circularidade

$$
I c=\frac{12,57 x A}{P^{2}}
$$

- Índice Comprimento e a área da bacia

$$
I_{c o}=\frac{\mathrm{P} / \pi}{\sqrt{A}}
$$

- Densidade de Drenagem

$$
D d=\frac{L}{A}
$$

- Extensão média do escoamento superficial

$$
l=\frac{A}{4 L}
$$

\section{RESULTADOS E DISCUSSÃO}

No que se trata à pedologia encontrada na microbacia, de modo geral, destacam-se, três tipos de solos (Figura 2). LUVISSOLOS (T) constituídos por material mineral, apresentando horizonte B textural e não hidromórficos, que não sofreram influência da água na sua formação. Em $2^{\circ}$ nível pelos LUVISSOLOS CRÔMICO (TC). LATOSSOLOS (L) constituídos por material mineral, apresentando horizonte B latossólico precedido de qualquer tipo de horizonte A, dentro de $200 \mathrm{~cm}$ da superfície do solo ou dentro de $300 \mathrm{~cm}$ se o horizonte A apresentar mais que $150 \mathrm{~cm}$ de espessura. Em $2^{\circ}$ nível pelos LATOSSOLOS BRUNOS (LB). Como também, NEOSSOLOS (R) 
que são poucos evoluídos constituídos por material mineral ou parte orgânica com menos de $20 \mathrm{~cm}$ de espessura, não apresentam qualquer tipo de horizonte B. Subdivide-se em $2^{\circ}$ nível pelos NEOSSOLOS FLÚVICOS (RY), NEOSSOLOS LITÓLICOS (RL) NEOSSOLOS REGOLÍTICOS (RR).

De um do ponto de vista geomorfológico, a microbacia do Riacho Chafariz no que diz respeito à sua altitude, configura-se com uma área com predomínio de elevações em torno de 300m a 800m. Especificamente, nas porções Sul, Sudoeste e Leste (Figura 3). A partir desta predominância de altitude no relevo da microbacia, se pode afirmar que o mesmo é irregular e heterogêneo, pois apresenta resquícios do Planalto da Borborema (parte sul) e bordas situadas a sudeste, caracterizadas pelas altitudes elevadas, com vários pontos escarpados e feições de vales onde estão as nascentes dos afluentes do Riacho Chafariz.

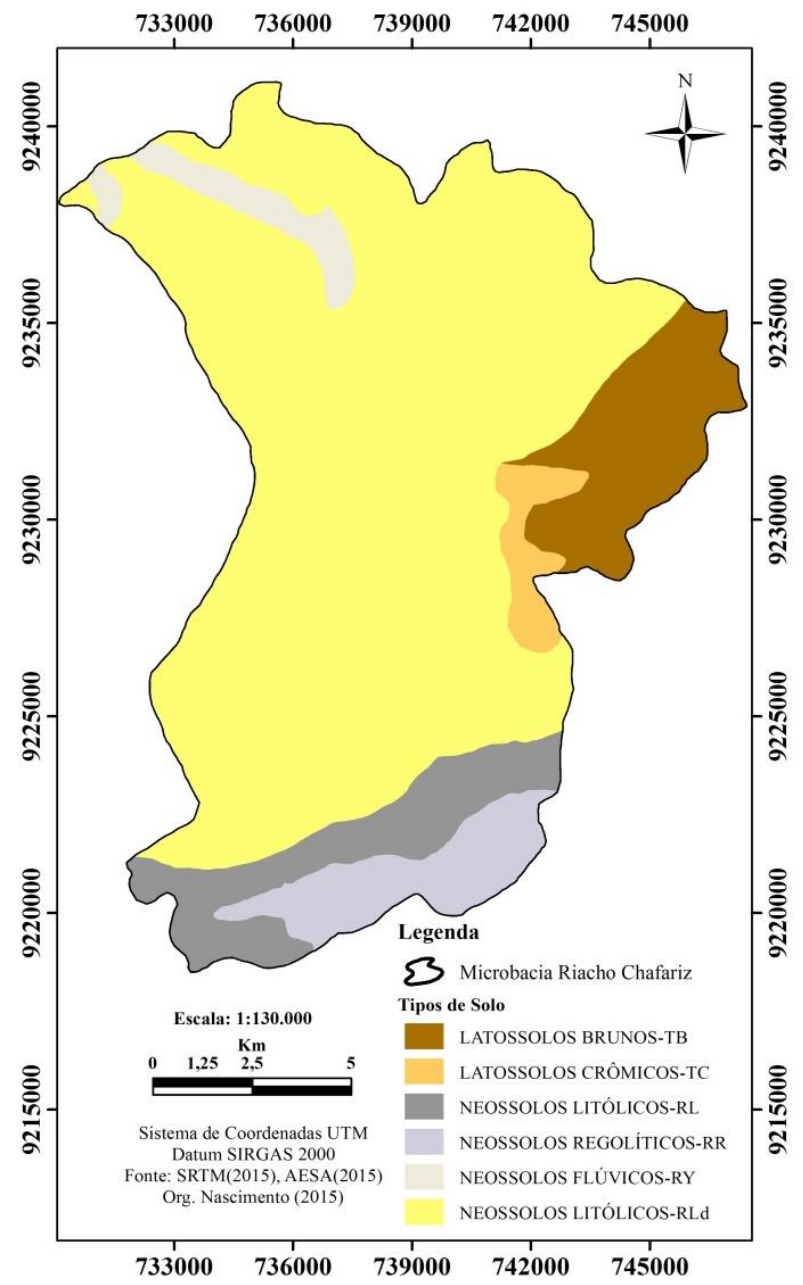

Figura 2 - Mapa de tipos de solos da microbacia hidrográfica do Riacho Chafariz. Fonte: AESA (2015)/SRTM (2015). Elaborado por Nascimento et al. (2016).

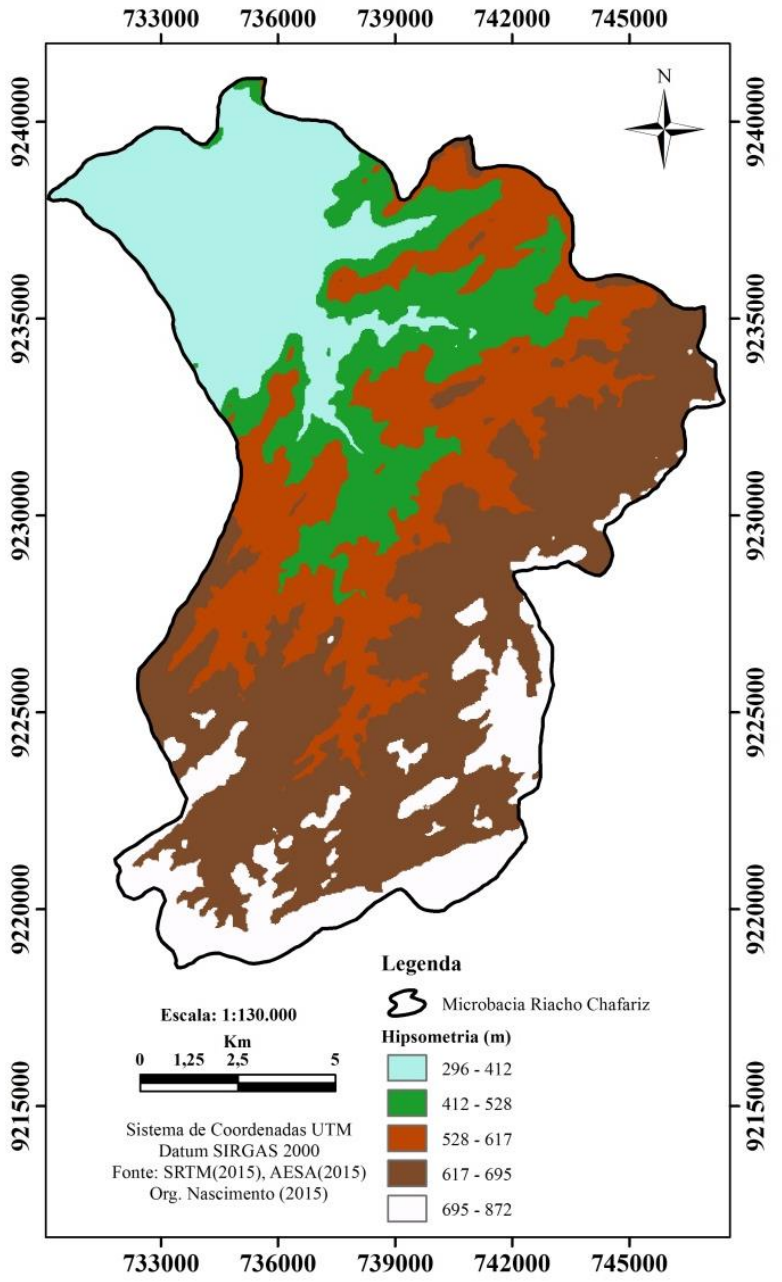

Figura 3 - Mapa hipsométrico da microbacia hidrográfica do Riacho Chafariz. Fonte: AESA (2015)/SRTM (2015). Elaborado por Nascimento et al. (2016). 
As inclinações da superfície do terreno em relação ao plano horizontal, de modo geral, encontra-se no intervalo das classes de declividade entre plano a ondulado, o que aponta que a bacia tem potencial de processos de deposição de sedimentos (Figura 4). Ao considerar que os aspectos geomorfológicos além de influenciar nas condições climáticas e de vegetação da região, também contribuem para a configuração dos padrões de drenagem. Diante desta afirmativa, a partir das análises realizadas pode-se dizer que o padrão de drenagem da microbacia hidrográfica do Riacho Chafariz, apresenta uma estrutura dendrítica e classificação hierárquica dos canais fluviais de ordem 5 (Figura 5). Logo, tal configuração pode ser resultante da geologia na qual está inserida, como também, das características do solo presentes, caracterizando uma área com predomínio de processos erosivos e deposição de sedimentos.

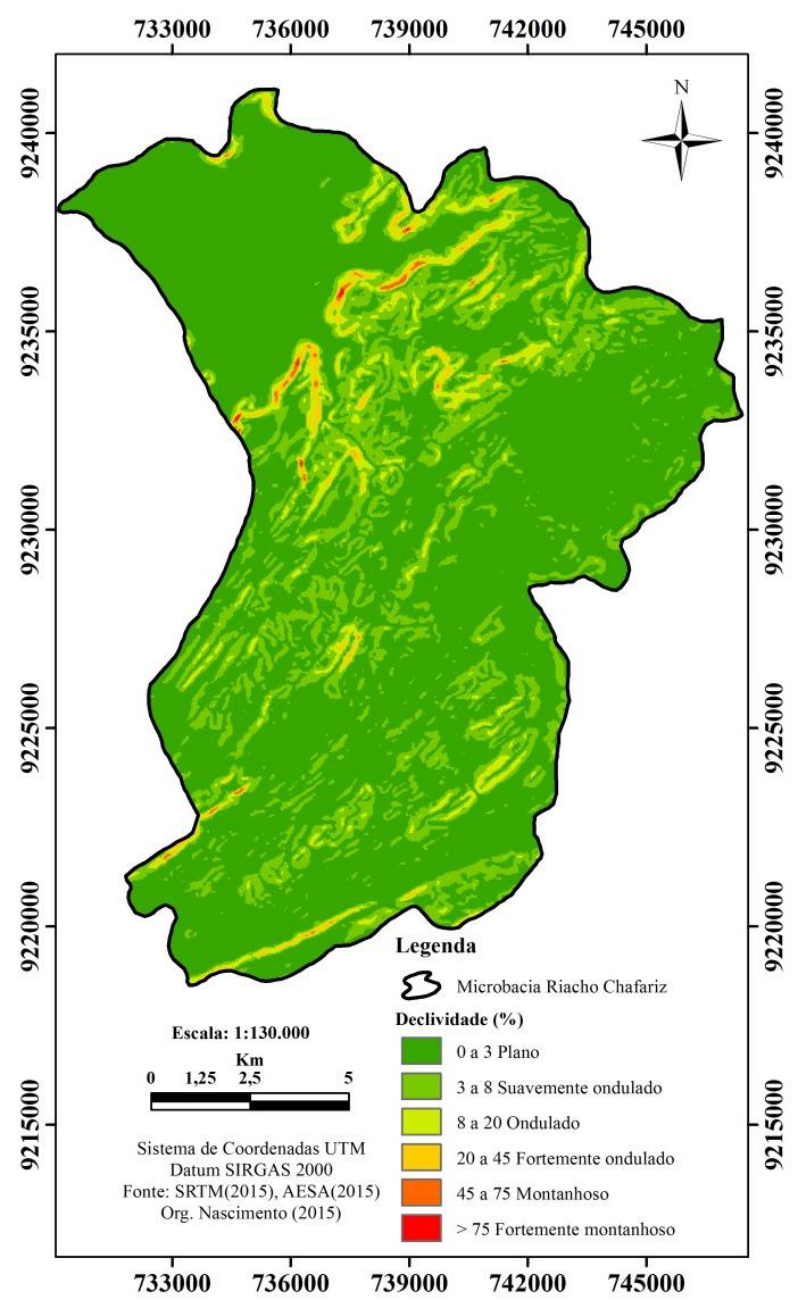

Figura 4 - Mapa de declividade da microbacia hidrográfica do Riacho Chafariz. Fonte: AESA (2015)/SRTM (2015). Elaborado por Nascimento et al. (2016).

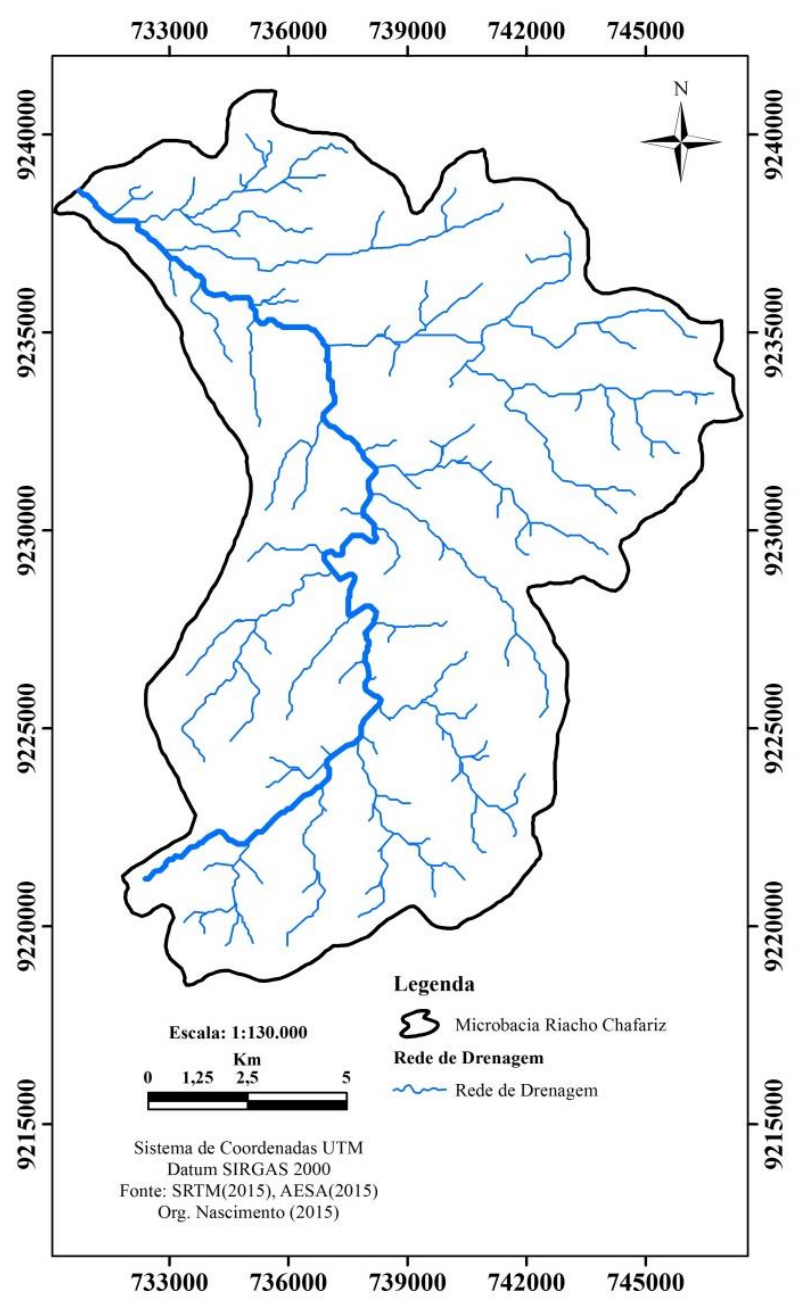

Figura 5 - Mapa de rede de drenagem da microbacia hidrográfica do Riacho Chafariz. Fonte: AESA (2015)/SRTM (2015). Elaborado por Nascimento et al. (2016). 
No que diz respeito à análise morfométrica, conforme as características hidrográficas, a referida microbacia apresenta uma densidade da rede de drenagem considerada pobre, com valor de $0.14 \mathrm{Km} / \mathrm{Km}^{2}$. Curso de água principal alinhado na direção SE-NO, isto implica afirmar que a microbacia tem baixa relação entre o comprimento dos rios e a área, portanto, um eficiente escoamento e boa infiltração, caracterizando-se com uma microbacia com pouca possibilidade de enchentes.

A extensão média do escoamento superficial apontou um valor de $1,70 \mathrm{Km}$, que corresponde à distância média em que a água da chuva escoaria, no caso de ocorrência em linha reta, desde o local onde caiu a precipitação até o ponto mais próximo no leito de um curso d'água qualquer da microbacia. Para as demais características geométricas, os resultados demonstraram que a referida microbacia possui uma área de drenagem de $374.61 \mathrm{Km}^{2}$ e o perímetro de $116.21 \mathrm{Km}$. Com base nestes dados, foram calculados os índices mais importantes para a caracterização morfométrica da microbacia (Tabela 1).

Tabela 1 - Características geométricas da microbacia hidrográfica do Riacho Chafariz. Fonte: Elaborada por Nascimento et al. (2015).

\begin{tabular}{ll}
\hline Índices Morfométricos & Valor \\
\hline $\mathrm{K}_{c}-$ Coeficiente de Compacidade & 1,52 \\
$\mathrm{~K}_{f}$ - Fator de Forma & 0,216 \\
$\mathrm{I}_{c}$ - Índice de Circularidade & 0.437 \\
$\mathrm{I}_{C O}$ - Índice entre o comprimento e & 1.70 \\
a área da bacia & \\
\hline
\end{tabular}

Os índices morfométricos geométricos demonstraram que a microbacia do Riacho Chafariz apresenta uma baixa probabilidade a grandes enchentes, como expressa o valor do $\mathrm{K}_{c}$, maior que 1,5. O que é comprovado, quando se correlaciona ao valor resultante de $\mathrm{K}_{f}$, menor que 0,5. Portanto, esta condição apresentada pela microbacia, atribui-se ao fato do seu formato geométrico, ser mais alongada que circular. Afirmativa esta, evidenciada quando analisado o resultado do valor do $\mathrm{I}_{c}$ quando menor que 0,51 a microbacia tende a ser alongada, como também pelo valor do $\mathrm{I}_{C O}$ que ao ser maior que 1,00 mais alongada será a microbacia.

\section{CONSIDERAÇÕES FINAIS}

Os resultados obtidos a partir dos procedimentos metodológicos aplicados neste trabalho possibilitaram expor uma compreensão inicial das características físicas da microbacia hidrográfica do Riacho Chafariz. Sendo assim, o uso das técnicas de geoprocessamento, mostrou-se satisfatório, uma vez que, permitiram gerar informações importantes sobre a referida microbacia atendendo ao 
que se propôs no trabalho. Como também, comprovou sua eficiência quando usado em estudos ambientais.

Sobre as informações geradas, pode-se afirmar que a referida microbacia apresenta uma forma geométrica alongada, sendo pouco sujeita a grandes enchentes, com rede de drenagem dendrítica e eficaz sistema de escoamento de água. Porém, com boa parte constituída por um relevo com significativa altitude, o que proporciona à microbacia uma propensão maior aos processos erosivos.

Tais informações a partir dos índices morfométricos utilizados podem servir de alguma forma como embasamento para possíveis tomadas de decisões no âmbito da microbacia. Mas, com uma ressalva, a de que para uma aplicação mais específica, se faz necessário a análise de outros índices, além dos que foram utilizados neste trabalho.

Portanto, ao avaliar os resultados da microbacia, considera-se a possibilidade de novos estudos ambientais sobre a área, tendo em vista sua importância para os municípios inseridos, em especial, o de Santa Luzia-PB. Esses estudos podem articular o uso do geoprocessamento aplicado na proposta de geração de áreas de preservação permanentes - APP's (nascentes, margens dos rios, etc), hidrológicos (análise precipitação) evolução espaço-temporal de uso e ocupação do solo (cobertura vegetal, degradação do solo), criação de um Comitê de Bacia. Além, dos que abordem de um ponto de vista da legislação ambiental, da gestão dos recursos hídricos (quantidade e qualidade) e da educação ambiental.

\section{REFERÊNCIAS}

CÂMARA, G.; BARbORSA, C. C. F.; DAVIS, C.; FONSECA, F. Conceitos básicos em geoprocessamento. Livros On-line, Teoria e Aplicações, INPE. 1999.

EMBRAPA. Serviço nacional de levantamento e conservação de solos (Rio de Janeiro, RJ). Súmula da $10^{\circ}$ Reunião Técnica de Levantamento de Solos. Rio de Janeiro, 1979. 83p. (EMBRAPA-SNLCS. Micelânea, 1).

EMBRAPA. SIBCS - Sistema brasileiro de classificação de solos. $3^{\circ}$ Ed. Centro Nacional de Pesquisa de Solos. Rio de Janeiro: EMBRAPA-SPI, 2013. 353p.

NOVAES, L. F.; AMARAL, L. G. H.; TERRA, A. A. Determinação das características físicas da bacia hidrográfica do rio Corrente. In: Congresso Nacional de Irrigação e Drenagem, 2004, Porto Alegre. Anais XIV CONIRD. 2004.

ROCHA, J. S. M. Manual de manejo integrado de bacias hidrográficas. Santa Maria - Edições UFSM, 1991. $181 \mathrm{p}$. 
RODRIGUES, C.; ADAMI, S. Técnicas Fundamentais para o estudo de Bacias Hidrográficas. In: VENTURI, L. A. B. Praticando a Geografia: técnicas de campo e laboratório em geografia e análise ambiental. São Paulo: Oficina de textos, 2005, p. 147-166.

ROSA, R. Geotecnologias na geografia aplicada. Revista do Departamento de Geografia - FFLCUSP, São Paulo, n. 16, p. 81-90, 2005. Disponível em: http://citrus.uspnet.usp.br/rdg/ojs/index. php/rdg/article/view/55. Acesso em: 15 de jul. 2015.

STRAHLER, A. N. Quantitative analysis of watershed geomorphology. New Halen: Transactions: American Geophysical Union. v38. 1957. p913-920.

TUCCI, C. E. M. 1997. Hidrologia: ciência e aplicação. 2. ed. Porto Alegre: ABRH/ Editora da UFRGS, 1997.

VILlELA, S. M.; MATTOS A. Hidrologia Aplicada. São Paulo: Ed. McGraw-Hill do Brasil, 1975. 245p.

Recebido em: 14/08/2016

Aceito para publicação em: 01/10/2016 